Family Profile No. 20, 2019

\title{
Gray Divorce Rate in the U.S.: Geographic Variation, 2017
}

\section{Author: Colette Allred}

Although the overall divorce rate in the U.S. has declined, among those aged 50 and older it has roughly doubled since 1990 (FP19-13; Brown \& Lin, 2012). In this Family Profile, we estimate the national trend in divorce rates for adults aged 50 and older ("gray divorce") using the 1990 U.S. Vital Statistics Report and 1-year estimates from the American Community Survey (ACS) for the years 2008 to 2017 (the most recently available data). To examine state-level variation, we employ the 2013-2017, 5-year estimates from the ACS. This Family Profile supplements previously published profiles documenting the geographic variation in divorce rate overall (FP-17-24; FP-18-21).

\section{The Gray Divorce Rate, 2017 *}

- The gray divorce rate (represented as the number of divorces per 1,000 married women aged 50 and older) increased more than twofold between 1990 (4.9) and 2008 (10.7).

- Since 2008, the gray divorce rate has decreased slightly from 10.7 divorces per 1,000 married women aged 50 and older to 10.3 .

- In 2017, 344,755 women aged 50 and older divorced.

*The gray divorce rate $=[($ number of women aged $50+$ divorced in the past 12 months) / (number of women aged $50+$ divorced in the past 12 months + number of currently married women aged $50+$ )] $* 1,000$
Figure 1. Women's Gray Divorce Rate, 1990-2017

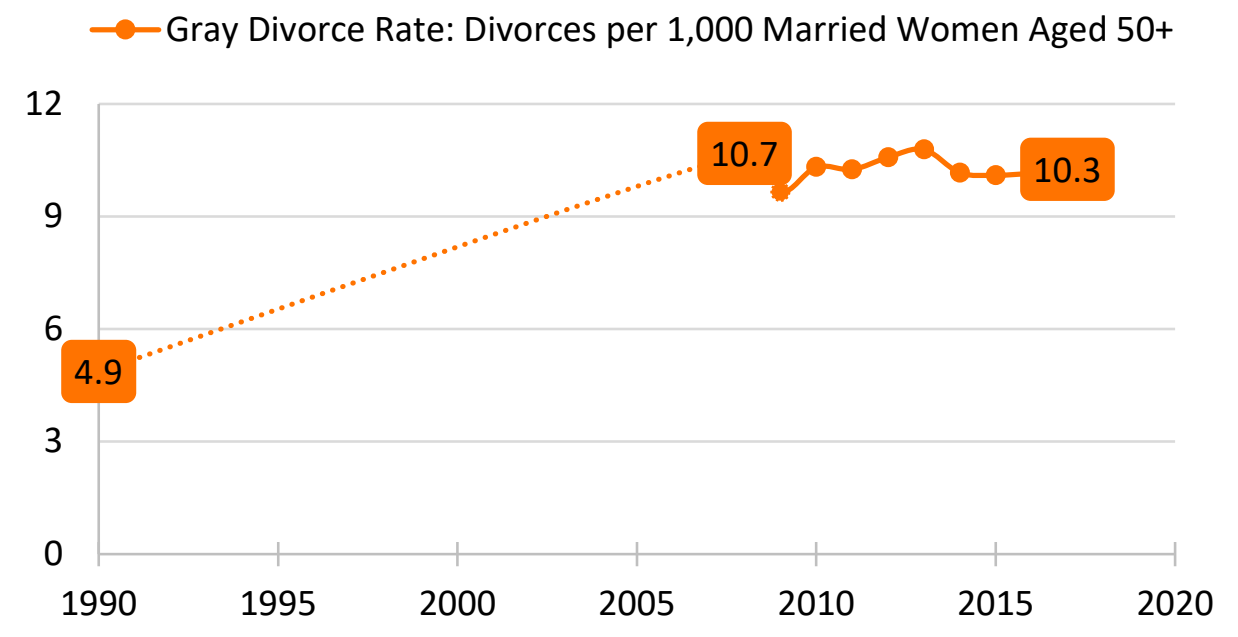

Source: NCFMR analyses of 1990 National Center for Health Statistics; 2008-2017, U.S. Census Bureau, American Community Survey, 1-yr est.

\section{Five Highest and Lowest Gray Divorce Rates, 2017}

- South Dakota had the lowest gray divorce rate, with about 5 marriages per 1,000 ending in divorce among women aged 50 and older.

- Delaware had the highest gray divorce rate in 2017, with over 13 marriages per 1,000 ending in divorce among women aged 50 and older.

o Delaware's gray divorce rate was more than twice the rate of South Dakota's.

\begin{tabular}{|clr|}
\hline \multicolumn{2}{|l|}{ Women's Highest and Lowest Gray Divorce Rates } \\
\hline 1 & Delaware & 13.4 \\
2 & Nevada & 12.5 \\
3 & Kentucky & 12.3 \\
3 & Idaho & 12.3 \\
5 & New Mexico & 12.2 \\
& U.S. & 10.1 \\
46 & Rhode Island & 7.0 \\
47 & Nebraska & 6.5 \\
48 & Montana & 6.4 \\
49 & Iowa & 6.3 \\
50 & South Dakota & 5.1 \\
\hline
\end{tabular}

Source: NCFMR analyses of U.S. Census Bureau, 2017 American Community Survey, 5-yr est. 
Figure 2. State Variation in the Divorce Rate per 1,000 Married Women Aged 50+ by Quartile, 2017

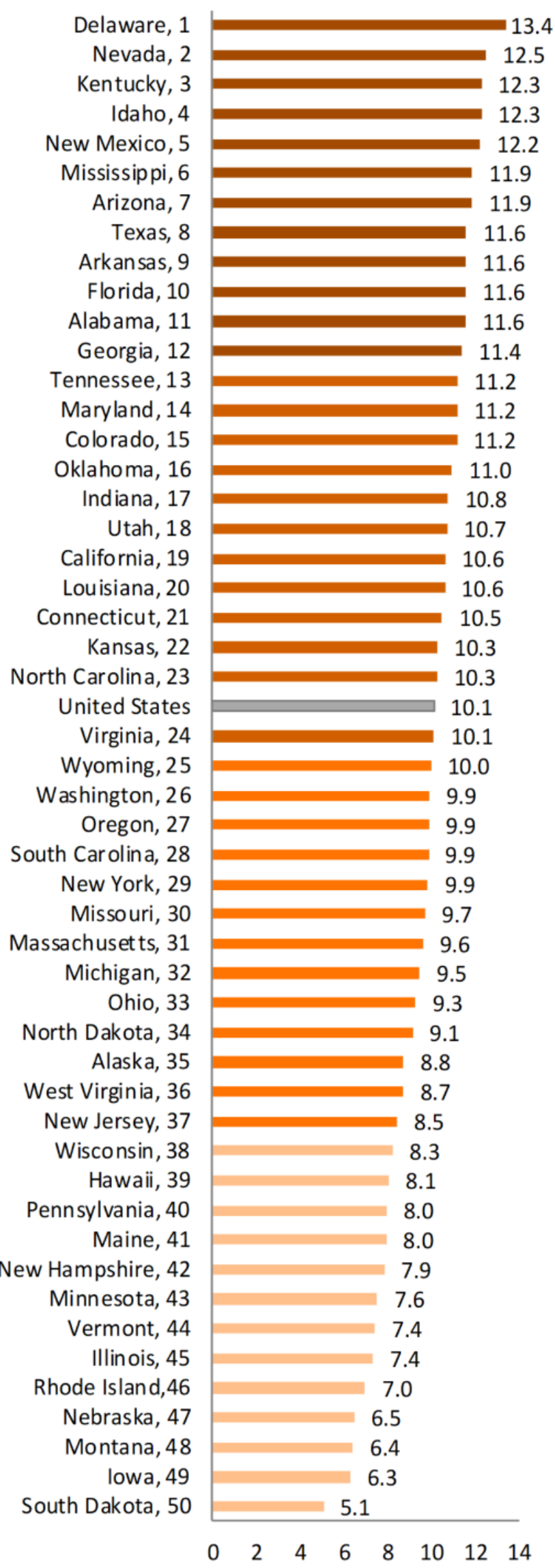

- The 12 states with the highest gray divorce rates (making up the $1^{\text {st }}$ quartile) had rates of at least 11.4 divorces per 1,000 married women aged 50 and older in 2017.

- The 13 states that experienced the lowest gray divorce rates (making up the $4^{\text {th }}$ quartile) in 2017 had fewer than 8.5 divorces per 1,000 women aged 50 and older.

- The gray divorce rates observed in North Carolina and Virginia were most similar to that of the overall gray divorce rate in the United States (10.1). 


\section{Geographic Variation in Gray Divorce Rates, 2017}

- States with the highest gray divorce rates (in the $1^{\text {st }}$ or $2^{\text {nd }}$ quartile) were predominantly found in the Southern and Western regions of the country.

o Exceptions include

Washington, Oregon, Montana, Wyoming, West Virginia, and South Carolina, which experienced gray divorce rates in the $3^{\text {rd }}$ or $4^{\text {th }}$ quartiles.

Figure 3. Geographic Variation of Women's Gray Divorce Rate, 2017

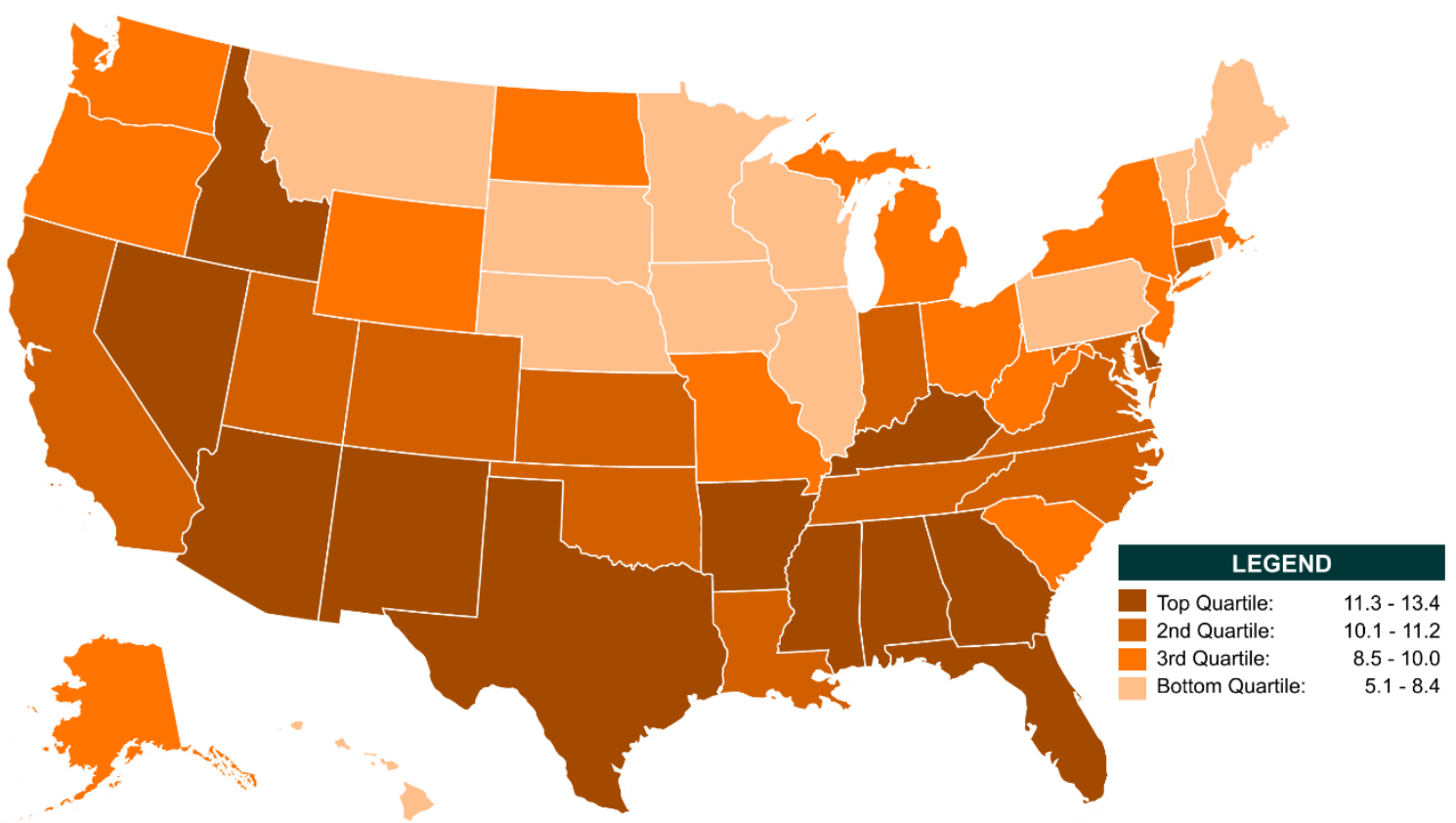

Source: NCFMR analyses of U.S. Census Bureau, 2017 American Community Survey, 5-yr est.

- States with the lowest

gray divorce rates (in the $3^{\text {rd }}$ or $4^{\text {th }}$ quartiles) were located in the Midwest and Northeast regions of the United States. o Exceptions include Kansas, Indiana, and Connecticut, which were in the first two quartiles of gray divorce rates.

\section{Data Sources:}

Clarke. S. C. (1995). Advanced report of final marriage statistics, 1989 and 1990. Monthly Vital Statistics Report, 42(12). National Center for Health Statistics. https://www.cdc.gov/nchs/data/mvsr/supp/mv43_12s.pdf

Ruggles, S., Flood, S., Goeken, R., Grover, J., Meyer, E., Pacas, J., \& Sobek, M. (2019). IPUMS USA: Version 9.0 [2013-2017, ACS 5-yr]. Minneapolis, MN: IPUMS. https://doi.org/10.18128/D010.V9.0

Ruggles, S., Flood, S., Goeken, R., Grover, J., Meyer, E., Pacas, J., \& Sobek, M. (2019). IPUMS USA: Version 9.0 [2017 ACS]. Minneapolis, MN: IPUMS. https://doi.org/10.18128/D010.V9.0

\section{References:}

Allred, C. (2019). Age variation in the divorce rate, 1990 \& 2017. Family Profiles, FP-19-13. Bowling Green, OH: National Center for Family \& Marriage Research.

Brown, S. L., \& Lin, I.- F., (2012). The gray divorce revolution: rising divorce among middle-aged and older adults, 1990-2010. Journals of Gerontology Series B: Psychological Sciences and Social Sciences, 67(6), 731-741.

Hemez, P. (2017). Divorce rate in the U.S.: Geographic variation, 2016. Family Profiles, FP-17-24. Bowling Green, OH: National Center for Family \& Marriage Research. https://doi.org/10.25035/ncfmr/fp-17-24.

Schweizer, V. (2018). Divorce rate in the U.S.: Geographic variation, 2017. Family Profiles, FP-18-21. Bowling Green, OH: National Center for Family \& Marriage Research. https://doi.org/10.25035/ncfmr/fp-18-21.

\section{Suggested Citation:}

Allred, C. (2019). Gray divorce rate in the U.S.: Geographic variation, 2017. Family Profiles, FP-19-20. Bowling Green, OH: National Center for Family \& Marriage Research. https://doi.org/10.25035/ncfmr/fp-19-20. 